\title{
INFILTRAÇÃO DA ÁGUA NO SOLO: PARTE II ACÚMULO DE ÁGUA SOBRE A SUPERFÍCIE DO TERRENO
}

\author{
Rubens Duarte Coelho ${ }^{1}$, Jarbas Honorio de Miranda $^{2}$ \& Sergio Nascimento Duarte ${ }^{3}$
}

\begin{abstract}
RESUMO
O presente trabalho teve como objetivo básico o desenvolvimento de uma metodologia para a quantificação do acúmulo de água na superfície do solo, em função da intensidade de precipitação dos emissores de um infiltrômetro de aspersores (IAS). Em condições de intensidade de precipitação abaixo da velocidade básica do solo (VIB) o microrrelevo superficial comportou-se de maneira estável, apresentando uma superfície espelhada crescente (acúmulo de água) sobre o solo, ao longo dos primeiros 120 min de ensaio e, em condições de intensidade de precipitação acima da velocidade básica (VIB) observou-se que a superfície espelhada estabilizava-se em menos de $30 \mathrm{~min}$, apresentando, posteriormente, a formação de canais preferenciais de escoamento de água sobre o solo (erosão laminar).
\end{abstract}

Palavras-chave: irrigação, aspersão, erosão, escoamento superficial

$$
\begin{aligned}
& \text { WATER INFILTRATION IN SOIL: PART II } \\
& \text { WATER ACCUMULATION OVER THE SOIL SURFACE }
\end{aligned}
$$

\begin{abstract}
This paper aims at the development of a new methodology for quantification of water over a soil surface, as a function of the precipitation intensity from a sprinkler irrigation system. The research was carried out at the experimental station belonging to Rural Engineering Department of the University of São Paulo (ESALQ), on a soil often used for traditional agricultural practices. The results obtained showed the existence of a relationship between the precipitation intensity over the area and the microrelief of the soil. Under conditions of low intensity, the microrelief stayed stable throughout the formation of puddles on the soil surface. Under conditions of high intensity, runoff was observed over the area, with the formation of small preferential water flow channels among the puddles, starting the laminar erosion process of the soil.
\end{abstract}

Key words: irrigation, sprinkler, erosion, runoff

\footnotetext{
Recebido em 25/06/1999, Protocolo 070/99

${ }^{1}$ Professor Doutor do Departamento de Engenharia Rural - ESALQ/USP. Av. Pádua Dias 11, CP 09, CEP 13418 - 900 , Piracicaba, SP. Fone: (0xx19) 429 4217, Fax: (0xx19) 433 0934. E-mail: rdcoelho@carpa.ciagri.usp.br

${ }^{2}$ Doutorando em Irrigação e Drenagem, DER-ESALQ/USP, Bolsista CNPq. E-mail: jhmirand@carpa.ciagri.usp.br

${ }^{3}$ Professor Doutor, DER-ESALQ/USP. E-mail: snduarte@carpa.ciagri.usp.br
} 


\section{INTRODUÇÃO}

A irrigação por aspersão é a maior responsável pelo incremento de área irrigada nas regiões sudeste e nordeste do Brasil, devido ao fato desse método de irrigação se adequar facilmente às diferentes condições de topografia, mão de obra e disponibilidade de capital. O sistema portátil de aspersão convencional, devido à sua versatilidade de operação é bastante utilizado no Estado de São Paulo, por agricultores arrendatários de terras que mudam freqüentemente de área, exigindo ajustes periódicos no projeto para se obter boa performance do equipamento nas diversas condições utilizadas.

Um dos principais problemas observados na prática refere-se à ocorrência de escoamento superficial em áreas irrigadas por sistemas de aspersão convencional, pelo fato do solo não ser capaz de absorver a intensidade de aplicação de água, proveniente dos aspersores. A solução deste problema pode ser alcançada pela alteração da intensidade de precipitação dos aspersores e pelo aumento da capacidade de absorção de água pelo solo. A primeira alternativa é mais rápida, porém poderá aumentar o tempo de operação do sistema e entrar em conflito com a jornada de trabalho dos empregados, enquanto a segunda alternativa poderá ser empregada a longo prazo e proporcionar melhor performance do sistema hidráulico previamente dimensionado. Segundo Bertol et al. (1987) a capacidade de absorção de água do solo poderá ser alterada por diferentes sistemas de preparo de solo (subsolagem, gradagem, aração, escarificação etc.) assim como pelas características de rugosidade da superfície do solo (cobertura vegetal morta). Em um experimento conduzido por Silva et al. (1986) em um solo classificado como Terra Roxa Estruturada, com $12 \%$ de declividade, foram observados maiores efeitos da cobertura vegetal no controle da erosão por parte do capimpangola, seguido da cana-de-açúcar, milho, feijão e algodão. Constatou-se, também, que outras práticas conservacionistas foram capazes de diminuir as perdas de solo por erosão. Independente do tipo de resíduo cultural sobre o solo, o aumento na porcentagem da cobertura do solo diminui acentuadamente a velocidade de escoamento superficial da água (Lopes et al., 1987). O resíduo cultural serve como barreira física, aumentando a tortuosidade de fluxo e impedindo que a água escoe livremente. Em áreas arrendadas para culturas irrigadas, não é comum a presença de resíduos vegetais sobre a superfície do solo, tampouco o emprego de sistemas alternativos de preparo de solo que não sejam os tradicionais, ou seja, aração e gradagem havendo, assim, predisposição ao escoamento superficial.

A maioria dos trabalhos de pesquisa sobre escoamento superficial em áreas agrícolas, limita-se a quantificar o volume de água da enxurrada, não se preocupando com as transformações ocorridas no microrrelevo superficial dos solos. O presente trabalho tem como objetivo o desenvolvimento de uma metodologia para a observação e quantificação das transformações ocorridas no microrrelevo do solo, em função da intensidade de precipitação de um sistema de irrigação do tipo aspersão convencional.

\section{MATERIAL E MÉTODOS}

Os ensaios foram conduzidos no Campo Experimental do Departamento de Engenharia Rural da ESALQ/USP, na mesma parcela com dimensões de $12 \times 12 \mathrm{~m}$ utilizada no experimento conduzido na Parte I deste trabalho, localizada em um solo classificado como Terra Roxa Estruturada - Série "Luiz de Queiroz", freqüentemente explorado com atividades agrícolas tradicionais, cuja superfície apresentava-se isenta de vegetação, em decorrência de uma gradagem leve realizada e da aplicação posterior do herbicida glifosato em bomba costal na sementeira das ervas daninhas emergentes, com 40 dias de antecedência ao início dos ensaios, período este em que ocorreu a acomodação natural da camada superficial do solo, induzida por duas precipitações naturais de baixa intensidade (18 e $29 \mathrm{~mm})$ no período.

A parcela experimental de $12 \times 12 \mathrm{~m}$, foi subdividida em 144 subparcelas de $1 \times 1 \mathrm{~m}$ e no perímetro da área foram cravadas estacas distanciadas $1 \mathrm{~m}$, que serviram de suporte para o entrelaçamento de uma corda de nylon $(\varnothing=2,5 \mathrm{~mm})$ de modo a demarcar cada subparcela e evitar pisoteamento na área. Nas posições superior e inferior da área, foram erguidos dois postos de observação com $5 \mathrm{~m}$ de altura cada um, conforme o croqui apresentado na Figura 1. O sistema de irrigação do tipo aspersão convencional idealizado, podia operar em quatro taxas de aplicação de água: 5,69, 11,38, 22,77 e 48,04 $\mathrm{mm} \mathrm{h}^{-1}$.

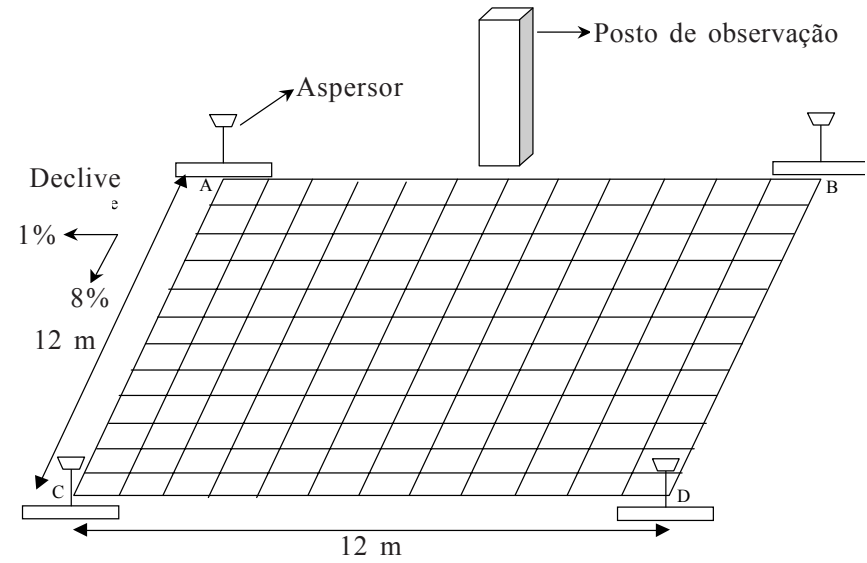

Figura 1. Diagrama esquemático da área experimental e disposição dos equipamentos no campo

Procurou-se manter constante a distribuição dos diâmetros de gotas do jato de água, utilizando-se sempre o mesmo diâmetro de bocal e pressão de operação dos aspersores utilizados. As três menores intensidades de precipitação foram obtidas com a

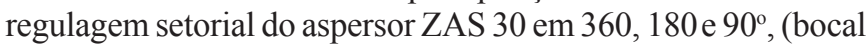
de $3,8 \mathrm{~mm}$ e pressão de $250 \mathrm{kPa}$ ). A maior intensidade de aplicação $\left(48,04 \mathrm{~mm} \mathrm{~h}^{-1}\right)$ foi alcançada somente com a operação simultânea de dois aspersores em cada posição (Coelho et al., 1992). Os ensaios foram realizados seqüencialmente do menor para o maior valor de intensidade de precipitação minimizando, assim, a formação de canais preferenciais de escoamento de água, que viessem a aumentar o escoamento superficial em baixas intensidades de precipitação.

Na Figura 2 estão representadas as curvas de nível na parcela experimental construídas a partir de um levantamento topográfico com 144 pontos no terreno (centro das subparcelas). Neste 
trabalho de pesquisa definiu-se "espelhamento da superfície do solo", como sendo a presença de uma lâmina de água sobre a superfície do solo, quer em repouso ou em movimento. A metodologia desenvolvida consistiu basicamente em quantificar a porcentagem de área espelhada na parcela experimental, decorridos 30, 60, 120 e 240 min de ensaio.

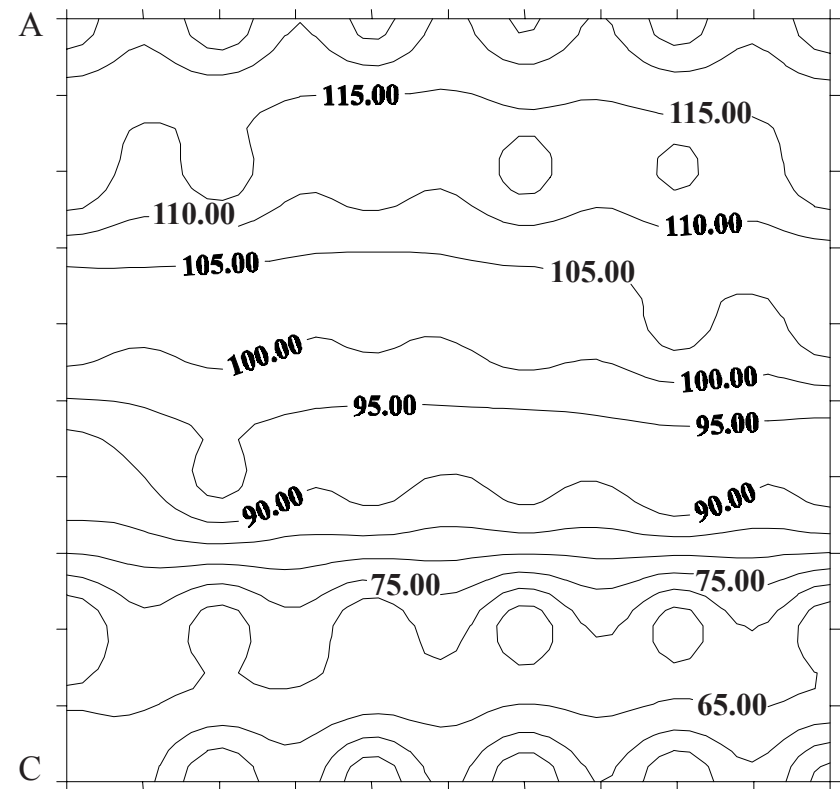

B

Figura 2. Curvas de nível na parcela experimental $(\mathrm{cm})$

Inicialmente, pensou-se em registrar a superfície espelhada do solo por uma fotografia panorâmica da parcela experimental, o que não foi possível devido à dificuldade de obtenção de uma luminosidade uniforme na área, que ressaltasse o espelhamento total. Sendo assim, optou-se pela observação visual do espelhamento da superfície do solo que, embora tivesse sido mais trabalhosa, proporcionou maior precisão nos resultados obtidos. O acompanhamento da superfície de espelhamento do solo foi efetuado por duas pessoas alojadas nos postos de observação instalados na área experimental, sendo cada uma responsável pela observação de 72 subparcelas. Em um papel quadriculado esboçava-se a superfície de espelhamento de cada subparcela, utilizando-se cores diferentes em cada período considerado (0-30, 30-60, 60-120 e 120-240 min). De posse do esboço final, representado em quatro cores distintas no papel quadriculado, foi possível, pela sobreposição de um papel vegetal, re-esboçar-se com tinta nankin, a superfície de espelhamento do solo nos tempos de 30, 60, 90, 120 e 240 min de aplicação de água. A quantificação da área espelhada em cada tempo considerado não era possível de ser efetuada com a utilização de um planímetro; então, optou-se por utilizar um "software" de processamento de imagem que, a partir de uma imagem capturada em um "scanner" portátil, fornecia a porcentagem de área sombreada da figura.

\section{RESULTADOS E DISCUSSÃO}

Conforme esperado, a medida em que aumentou o tempo de ensaio, houve acréscimo da área espelhada, indicando decréscimo na capacidade de absorção de água do solo (Figura 3).
$5,69 \mathrm{~mm} \mathrm{~h}^{-1}$ A. $30 \mathrm{~min}$

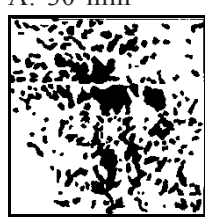

B. $60 \mathrm{~min}$

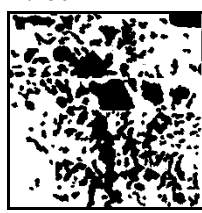

C. $120 \mathrm{~min}$

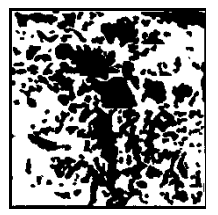

D. $240 \mathrm{~min}$

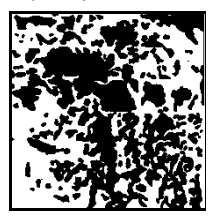

$11,38 \mathrm{~mm} \mathrm{~h}^{-1}$

$22,77 \mathrm{~mm} \mathrm{~h}^{-1}$

$48,04 \mathrm{~mm} \mathrm{~h}^{-1}$
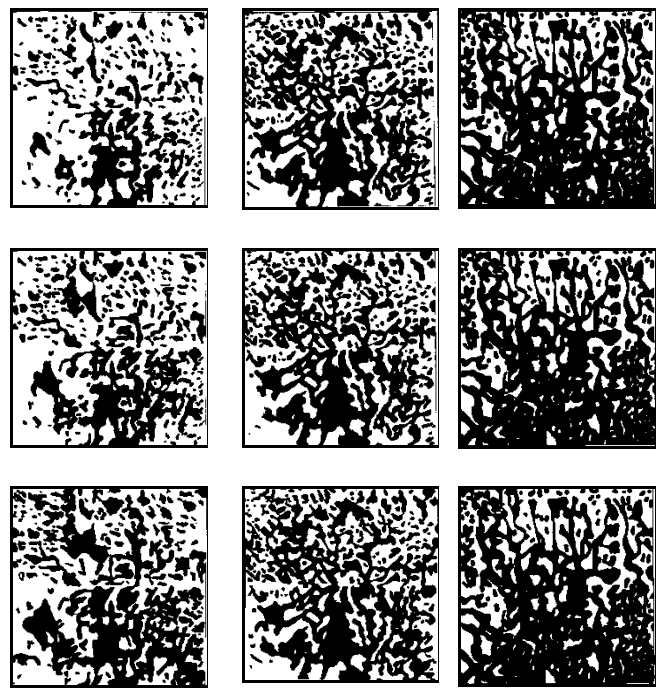

Figura 3. Área espelhada sobre o solo para os tempos de 30,60,

120 e 240 min de ensaio, para as intensidades de aplicação de $5,69,11,38,22,77$ e $48,04 \mathrm{~mm} \mathrm{~h}^{-1}$

$\mathrm{Na}$ intensidade de aplicação de $5,69 \mathrm{~mm} \mathrm{~h}^{-1}$, notou-se a formação de microbacias de acúmulo de água sobre a superfície do solo, que serviram como depósitos temporários de armazenamento de água. Nesta situação e para o tempo de 240 min de ensaio, quantificou-se um escoamento superficial de $0,49 \mathrm{~mm} \mathrm{~h}^{-1}$ sobre o terreno, com baixo potencial erosivo do solo.

$\mathrm{Na}$ intensidade de precipitação de $11,38 \mathrm{~mm} \mathrm{~h}^{-1}$, para os tempos de 30, 60, 90, 120 e 240 min de ensaio, a situação foi bastante parecida com a anterior, sendo que o único ponto a ser destacado é que no tempo de $240 \mathrm{~min}$ de ensaio a área espelhada aumentou $5,62 \%$, totalizando $61,23 \%$. Nesta situação verificouse escoamento superficial de $1,40 \mathrm{~mm} \mathrm{~h}^{-1}$ sobre o terreno, com baixo potencial erosivo do solo.

$\mathrm{Na}$ intensidade de precipitação bruta de $22,77 \mathrm{~mm} \mathrm{~h}^{-1}$, para o tempo de 240 min de ensaio, o escoamento superficial no terreno foi de 5,64 $\mathrm{mm} \mathrm{h}^{-1}$, com sensível potencial erosivo sobre o terreno. Notam-se, no sentido de maior declividade do terreno, interligações entre diversas microbacias de acúmulo de água evidenciando o surgimento de canais preferenciais de escoamento de água sobre o terreno.

$\mathrm{Na}$ intensidade de precipitação bruta de $48,04 \mathrm{~mm} \mathrm{~h}^{-1}$, para o tempo de 240 min de ensaio, o escoamento superficial no terreno foi de $29,97 \mathrm{~mm} \mathrm{~h}^{-1}$, com elevado potencial erosivo sobre o terreno. A área total espelhada do solo para o tempo de $240 \mathrm{~min}$ foi de $75,76 \%$, evidenciando-se canais preferenciais de escoamento de água sobre o solo com maior concentração na região inferior da parcela experimental.

A velocidade estabilizada de infiltração de água no solo (VIB) avaliada pela diferença entre a taxa de aplicação líquida estimada e o escoamento superficial medido com auxílio do coletor de escoamento superficial da área, variou entre 13,26 e 
$14,85 \mathrm{~mm} \mathrm{~h}^{-1}$, de acordo com os resultados discutidos na Parte I deste trabalho. Analisando-se a superfície espelhada da Figura 3, observa-se que, mesmo em condições de intensidade de aplicação de água dos aspersores, abaixo da velocidade de infiltração básica do solo (VIB) formaram-se microbacias de acúmulo de água na superfície do solo, evidenciando a importância do condicionamento do microrelevo superficial do terreno (presença de depressões confinadas) no controle do escoamento superficial na área, pois causa o aumento do potencial total da água sobre o terreno (potencial pressão) que irá aumentar a taxa de infiltração média de água no terreno e evitar o selamento superficial do solo, pelo amortecimento do choque direto das gotas d'água contra a superfície do terreno.

É provável que a formação de canais preferenciais de escoamento de água no terreno em decorrência das elevadas intensidades de precipitação na área $\left(22,77 \mathrm{e} 48,04 \mathrm{~mm} \mathrm{~h}^{-1}\right)$, viesse aumentar o deflúvio superficial nas menores intensidades de precipitação $\left(5,69\right.$ e 11,38 $\left.\mathrm{mm} \mathrm{h}^{-1}\right)$. Esta situação pode ocorrer no campo, em decorrência de precipitações naturais de elevada intensidade na área, predispondo o solo a uma susceptibilidade maior à erosão.

Na Figura 4 são apresentadas, na forma gráfica, as porcentagens de área espelhada nas quatro intensidades de aplicação de água dos aspersores. Constata-se que, para as baixas intensidades de aplicação ensaiadas $\left(5,69 \mathrm{e} 11,38 \mathrm{~mm} \mathrm{~h}^{-1}\right)$ a porcentagem de área espelhada aumentou progressivamente entre 30 e 120 min de ensaio, tendendo a se estabilizar no tempo de $240 \mathrm{~min}$. No caso das intensidades acima da faixa da VIB $\left(22,07 \mathrm{e} 48,04 \mathrm{~mm} \mathrm{~h}^{-1}\right)$ verifica-se que houve estabilização da superfície de espelhamento do solo durante os primeiros $30 \mathrm{~min}$

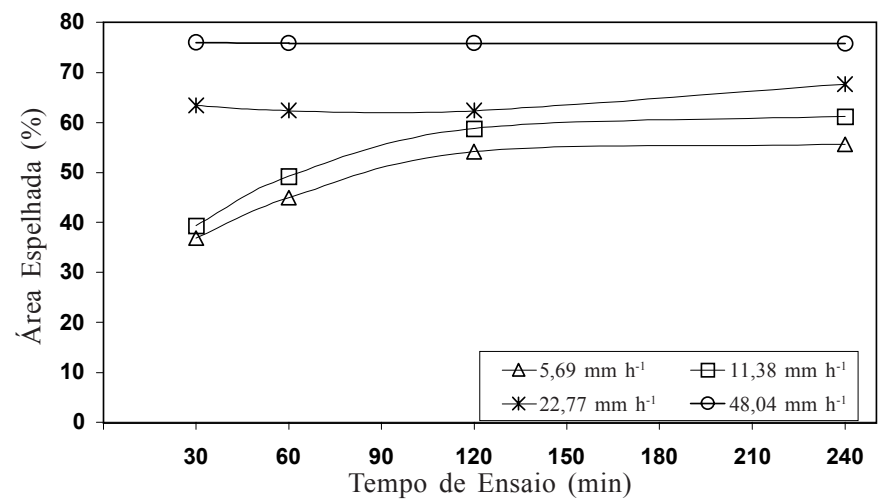

Figura 4. Porcentagem de área espelhada na superfície do solo, nas intensidades de aplicação de água dos aspersores de $5,69,11,38,22,77$ e $48,04 \mathrm{~mm} \mathrm{~h}^{-1}$, para o tempo de ensaio de $240 \mathrm{~min}$ de ensaio. Este comportamento observado da área espelhada, deve ser considerado decisivo na determinação da VIB de um solo ensaiado com um infiltrômetro de aspersores (IAS), pois é muito simples e barato de ser instalado este equipamento no campo, dando uma resposta muito confiável e rápida quanto à máxima taxa de aplicação de água que poderá ser adotada em um sistema de irrigação por aspersão, do tipos portátil e fixo.

\section{CONCLUSÕES}

1. Em condições de baixa intensidade de precipitação ocorre a formação de microbacias de acúmulo de água sobre a superfície do solo; já em condições de elevada precipitação sobre o terreno, ocorre rompimento seqüencial dessas microbacias, induzindo à formação de canais preferenciais de escoamento de água e aumentando, conseqüentemente, o escoamento superficial.

2. Intensidades de precipitação acima da velocidade de infiltração básica de água no solo, promovem um rápido espelhamento da superfície ( $<30 \mathrm{~min}$ ) que se mantém constante com o passar do tempo (30 a $240 \mathrm{~min}$ ). Intensidades de precipitação abaixo da VIB propiciam aumento progressivo da área espelhada (30 a $120 \mathrm{~min}$ ). A metodologia proposta de quantificação da área espelhada na superfície do solo, mostrou-se sensível, prática e eficiente.

\section{REFERÊNCIAS BIBLIOGRÁFICAS}

BERTOL, I.; COGO, N.P.; LEVIEN, R. Relações da erosão hídrica com métodos de preparo de solo, na ausência e na presença de cobertura por resíduo cultural de trigo. Revista Brasileira de Ciência do Solo. Campinas. v.11, p.187-192, 1987.

COELHO, R.D.; VICCINO, J.R.; SILVA, V.M. da. Velocidade de infiltração da água no solo - aspectos práticos: Infiltrômetro de anéis x Infiltrômetro de aspersores. In: XXVI CONGRESSO BRASILEIRO DE ENGENHARIA AGRÍCOLA, Santa Maria, 1992, Anais... Santa Maria: UFSM, 1992.

LOPES, P.R.C.; COGO, N.P.; CASSOL, E.A. Influência da cobertura vegetal morta na redução da velocidade e na distribuição de tamanho dos sedimentos transportados. Revista Brasileira de Ciência do Solo. Campinas, v.11, p.193-197, 1987.

SILVA, I.F. da; IANDRADE, A.P.; CAMPOS FILHO, O.R.; OLIVEIRA, F.A.P. Efeito de diferentes coberturas vegetais e de práticas conservacionistas no controle da erosão. Revista Brasileira de Ciência do Solo. Campinas, v.10, p.289-292, 1986. 